\section{Plataformas algorítmicas e economia da desinformação ${ }^{1}$}

Julio Cesar Lemes de Castro

\section{Resumo:}

Este artigo de reflexão teórica, ancorado em pesquisa bibliográfica, propõe-se a demonstrar que as plataformas algorítmicas são espaços propícios à desinformação, em virtude da maneira como suas características tecnológicas são instrumentalizadas por seu modelo de negócios, resultando na prevalência do valor-algoritmo sobre o valor-notícia. Para apreender tal instrumentalização, bem como os seus efeitos no que tange à desinformação, o modus operandi das plataformas é analisado sob quatro rubricas. Onimediação desigual é a proliferação das instâncias de mediação, cada usuário atuando em alguma medida como influenciador e sendo influenciado por incontáveis outros. Arena de atenção consiste na condição de disputa permanente entre os usuários que suplanta a esfera pública. Exposição calibrada designa - em lugar de exposição seletiva, câmaras de eco ou bolhas de filtro - o direcionamento ponderado dos conteúdos exibidos a cada usuário. E máquinas de guerra híbrida são mobilizações desestabilizadoras cujo comando está fora do controle das plataformas.

Palavras-chave: Algoritmos. Plataformas. Desinformação.

\section{Algorithmic platforms and economics of disinformation}

\begin{abstract}
:
This article of theoretical reflection, which is anchored in bibliographic research, aims to demonstrate that the algorithmic platforms are propitious spaces to disinformation, given the way their technological characteristics are instrumentalized by their business model, resulting in the prevalence of the algorithm value over the news value. In order to apprehend such instrumentalization, as well as its effects on disinformation, the modus operandi of platforms is analyzed under four aspects. Unequal omnimediation is the proliferation of instances of mediation, each user acting to some extent as an influencer, while also being influenced by countless others. The arena of attention consists of the condition of permanent dispute among users, which supersedes the public sphere. Calibrated exposure designates - in lieu of selective exposure, echo chambers or filter bubbles - the weighted targeting of the content displayed to each user. And hybrid war machines are destabilizing mobilizations whose command is beyond the platforms' control.
\end{abstract}

Keywords: Algorithms. Platforms. Disinformation.
Recebido em: 30.09 .20

Aprovado em: 24.08.21

Julio Cesar Lemes de Castro

Pesquisador do Laboratório de Teoria Social, Filosofia e Psicanálise (Latesfip-USP). Doutor em Comunicação e Semiótica (PUC-SP), com pós-doutorados em Psicologia Social (USP), Comunicação e Cultura (UFRJ) e Comunicação e Cultura (Uniso).

E-mail: julio@jclcastro. com.br

${ }^{1}$ Uma versão inicial deste artigo foi apresentada no XLIII Congresso Brasileiro de Ciências da Comunicação (Intercom), realizado virtualmente em Salvador (BA) de 1 a 10 de dezembro de 2020.

Estudos em Jornalismo e Mídia v.18, n.2, jul./dez. 2021.

ISSNe 1984-6924 
tualmente, assistimos à crescente relevância de plataformas reguladas por algoritmos e pertencentes a grandes corporações, como Facebook e Google, que podem ser consideradas "plataformas algorítmicas" (CASTRO, 2019a), nas quais se exerce uma "governança algorítmica" (CASTRO, 2018). Nesse cenário, equivalente a um "capitalismo de plataforma" (SRNICEK, 2017), uma porção notável dos encargos da distribuição e inclusive da produção de notícias é transferida das empresas jornalísticas tradicionais para as plataformas. É verdade que os conteúdos encontrados nas plataformas muitas vezes são de teor pessoal, ou familiar, ou envolvendo pequenos grupos de conhecidos. A eles, no entanto, se misturam conteúdos ostensivamente noticiosos, extraídos de fontes jornalísticas. Também são conspícuos nas redes conteúdos que podem ser associados de um modo ou de outro a notícias, em postagens de jornalistas, especialistas, políticos ou celebridades; postagens que mesclam elementos noticiosos a ingredientes de marketing e entretenimento; postagens que repercutem a ponto de virarem notícia; ou postagens de usuários comuns contendo informações de interesse mais geral. Esse embaralhamento das balizas entre o que é notícia ou não pavimenta o caminho para conteúdos que se apresentam como notícias mas não seguem preceitos jornalísticos, isto é, não resultam de apuração, nem se estribam em evidências, abrigando doses variadas de ficção. Tais conteúdos são comumente designados como "fake news"; mas, para evitar a conotação de algo falso apenas acidentalmente, prefere-se aqui traduzir essa expressão por "notícias fraudulentas". E, de forma mais abrangente, recorre-se ao termo "desinformação" - de uso mais tradicional, consignado em dicionários - para enfatizar o aspecto enganoso, deliberado e sistemático presente com frequência nesse material. As notícias fraudulentas são tomadas, portanto, como exemplares do fenômeno geral da desinformação.

Como é bem-sabido no campo jornalístico, a definição do que constitui notícia e a triagem das notícias que serão publicadas por um veículo derivam de decisões editoriais, que levam em conta critérios de noticiabilidade. No trabalho pioneiro de Galtung e Ruge (1965), os predicados de um acontecimento que contribuem para a sua noticiabilidade são denominados "valores-notícia" (news values) e arranjados numa matriz com doze componentes: frequência, amplitude, inequivocidade, significância, consonância, imprevisibilidade, continuidade, composição, referência a nações de elite, referência a pessoas de elite, referência a pessoas e referência a algo negativo. Desde então, essa classificação tem sido retomada e repensada por diversos autores, como Harcup e O’Neill (2001; 2017). Valor-notícia é, pois, um conceito já sobejamente explorado na teoria do jornalismo.

Enquanto os órgãos jornalísticos operam com base em uma curadoria editorial, nas plataformas a curadoria está a cargo dos algoritmos, os quais decidem o que será mostrado a cada usuário e em que ordem. Por analogia com o valor-notícia, pode-se dizer que nas plataformas vigoram o valor-algoritmo, que consiste no peso distinto estipulado pelos algoritmos para cada tipo de conteúdo que nelas circula (CASTRO, 2019b). Assim como o valor-notícia se subordina aos critérios de noticiabilidade adotados em cada veículo, o valor-algoritmo de um conteúdo varia para cada usuário em cada plataforma, ou até em cada setor de uma plataforma (por exemplo, um grupo no Facebook). Em tese, o valor-algoritmo é mais passível de mensuração do que o valor-notícia, devido aos registros quantitativos existentes nas plataformas, porém sua tradução em cifras demandaria ponderar todas essas variáveis, além do fato de que existem diferentes registros para cada conteúdo (montante de visualizações, curtidas, comentários, compartilhamentos etc.). Por isso, não se pretende aqui propor qualquer medida empírica nesse sentido, empregando-se valor-algoritmo de forma meramente conceitual, como se usa valor-notícia.

O crivo editorial é sensível, obviamente, a juízos de índole comercial, mas a preocupação com a credibilidade compele os veículos jornalísticos e seus pro- 
fissionais a sopesar fatores como precisão e qualidade da notícia. Quanto às plataformas, à parte aquilo que não é vetado por contrariar os termos de serviço, o critério de avaliação aplicado aos conteúdos é de ordem pecuniária, valorizando-se o que pode trazer maior retorno financeiro. Em contraste com o lema centenário do New York Times, "todas as notícias adequadas para publicar", podemos dizer que nelas vigora, na prática, o lema "todas as notícias adequadas para clicar" (MUNGER, 2020). O valor-algoritmo tem, destarte, um espírito primordialmente econômico. Se nos órgãos jornalísticos o valor-notícia serve de fundamento para uma economia da notícia, nas plataformas o valor-algoritmo é a pedra de toque do que seria uma economia da informação. Na primeira, a notícia figura como mercadoria, seja em termos de produção, seja em termos de distribuição, enquanto a segunda trata como mercadorias conteúdos que não são necessariamente notícias na acepção convencional. Entretanto, o que se tenciona demonstrar aqui é que, em decorrência das peculiaridades da governança algorítmica exercida nas plataformas, condicionada numa boa medida por seu modelo de negócios, tal economia da informação se configura, em grau apreciável, como uma economia da desinformação, na medida em que a produção e a distribuição da desinformação se revelam economicamente mais atraentes que as da informação.

Em síntese, o argumento deste artigo de reflexão teórica, ancorado em pesquisa bibliográfica que referencia levantamentos empíricos, é que as plataformas algorítmicas favorecem a desinformação, por causa da maneira como suas características tecnológicas são instrumentalizadas por seu modelo de negócios. Tipicamente, esse modelo requer a captação de dados dos usuários, utilizados para personalizar as ofertas comerciais que lhes são dirigidas. Quanto maior for a participação dos usuários, maior será a quantidade de dados captada. A instrumentalização das plataformas, visando fomentar essa participação, será investigada sob quatro rubricas, que correspondem a um esforço para precisá-la conceitualmente: onimediação desigual, arena de atenção, exposição calibrada e máquinas de guerra híbrida. E, em todas essas rubricas, será averiguado o imbricamento com a desinformação. Aprofundar a análise de cada uma demandaria espaço adicional, mas o interesse principal do trabalho é sustentar em diversas frentes o argumento geral sobre o caráter propício à desinformação das plataformas algorítmicas. Cumpre frisar que, não obstante as várias plataformas diferirem entre si, são seus aspectos em comum que merecerão realce.

\section{Onimediação desigual}

No final do século XIX, quando o tópico da dinâmica de funcionamento da massa galvaniza os teóricos, Gabriel de Tarde contrapõe o público, de natureza virtual e relativamente estável, à multidão, que presume proximidade física e efemeridade. Para ele, a consolidação do público é viabilizada pelo avanço da imprensa: "As grandes conversões das massas agora são operadas pelos jornalistas" (TARDE, 1910, p. 28). Suas formulações perfilam-se entre as principais referências em que se esteia a psicologia de massa de Freud (1967), na qual o líder se desincumbe de papel cardeal, a posição estratégica do jornalista em Tarde (1910) sendo equiparável à do líder em Freud. Já na teoria do jornalismo, essa posição aparece como a de mediação. Apoiando-se no insight de Kurt Lewin (1943) sobre a função de gatekeeping, White (1950) concebe o jornalista - a rigor, mais precisamente o editor - como o mediador que define o que é notícia e como esta chega à audiência.

Liderança e mediação não são, contudo, exclusividade dos jornalistas. Lazarsfeld e seus parceiros (LAZARSFELD; BERELSON; GAUDET, 1944; KATZ; LAZARSFELD, 1955) argumentam que o impacto dos meios de comunicação de massa sobre parcela considerável da população, no que tange à crenças e comportamentos, não se dá em linha direta, como um fluxo em uma etapa (one-step 
flow), mas por intermédio de líderes de opinião, como um fluxo em duas etapas (two-step flow). Em outras palavras, esses líderes retransmitem ideias recebidas da mídia para o círculo ao seu redor, filtrando-as ao seu modo.

O que sucede com o surgimento das plataformas? Através delas, o usuário pode assumir na prática a produção e a distribuição de informações, ao lado ou no lugar do jornalista, fenômeno descrito ordinariamente como desintermediação:

\begin{abstract}
Uma primeira desintermediação diz respeito à ruptura da relação de dominação com o leitor, que agora se torna produtor e distribuidor de informações ao vivo na Web por direito, do mesmo modo que o jornalista. [...] Quanto à segunda fase, ela é posta em andamento a partir do momento em que as ferramentas digitais permitem a todos os usuários da Internet publicar informações diretamente para qualquer outro usuário da Internet via redes sociais, sem passar pela intermediação da mídia e dos jornalistas (SCHERER, 2009, p. 65-66).
\end{abstract}

Seria mais preciso afirmar, todavia, que a mediação não desaparece, e sim se generaliza. Numa rede em que os nós se conectam em múltiplas direções, um nó sempre se situará entre outros. Isso significa que todos exercem alguma mediação, ainda que em graus díspares - temos uma onimediação desigual. Nas plataformas, continuam a existir líderes de opinião, que geram, difundem e/ou comentam conteúdos de todo tipo, noticiosos ou não. Há na verdade uma multiplicação de líderes, impulsionada pela mecânica das plataformas (CASTRO, 2016a). Certos líderes são superinfluenciadores, graças a seu alto número de seguidores e à ampla repercussão do que postam. Outros são "superparticipantes" (GRAHAM; WRIGHT, 2014), dada sua intensa atividade. No limite, cada usuário das plataformas é participante e influenciador, e os algoritmos garantem que cada ato seja computado e exerça alguma influência, portanto tenha algum impacto no valor-algoritmo. Se clico em um resultado de uma busca no Google, consulto a resenha de um livro na Amazon ou curto o que um amigo escreveu no Facebook, tudo isso terá algum peso, por ínfimo que seja, naquilo que o algoritmo selecionar futuramente para mim ou para outros.

$\mathrm{Na}$ onimediação desigual, o valor-algoritmo não está ligado forçosamente à qualidade da mediação, em termos de reputação e credibilidade. Por vezes, acontece justamente o contrário, o que pode traduzir-se de diferentes maneiras em desinformação.

Uma possível consequência da onimediação desigual é a perda dos parâmetros de confiabilidade do noticiário, outrora associados às fontes habituais de notícias. Segundo sondagem da Ipsos (2018), em 27 países, 60\% dos entrevistados, em média, acham que as organizações midiáticas publicam com frequência notícias fraudulentas, porcentagem que oscila de $30 \%$ na Alemanha a $82 \%$ na Argentina (no Brasil, são 73\%). Um experimento conjunto Gallup/Knight Foundation (2018) exibe uma compilação de notícias para participantes divididos em duas categorias, uma visualizando as fontes das notícias e outra não, e constata que os primeiros acreditam menos na veracidade do que leram. Isso indica uma predisposição contra as fontes, o viés mais negativo verificando-se entre os que menos confiam nos meios de comunicação tradicionais. A ausência de padrões para aferir a confiabilidade das fontes beneficia via de regra a desinformação. É essa a conclusão de Mocanu et al. (2015), lidando com uma amostra de 2,3 milhões de usuários do Facebook: aqueles que preferem fontes de informação alternativas aos veículos mainstream são mais suscetíveis a consumir notícias fraudulentas.

Outro possível efeito da proliferação da mediação é a adoção de parâmetros puramente comerciais. Exemplar nesse aspecto é a declaração de Neetzan Zimmerman (apud HOLMES, 2014, tradução nossa), que se notabiliza no site Gawker por sua habilidade em viralizar conteúdos: "Hoje em dia não é importante se uma história é real, a única coisa que realmente importa é se as pessoas clicam nela". 
Daí à desinformação há tão-somente um passo. O esquema de publicidade na Internet enseja que as notícias fraudulentas se transformem facilmente em filão de negócios. Isso é ilustrado por uma reportagem estampada no Washington Post, logo após a eleição de Donald Trump (McCOY, 2016), acerca do funcionamento de um site conservador especializado em notícias desse jaez, Liberty Writers. As matérias são escritas em poucos minutos, veiculadas online e apregoadas no Facebook, rapidamente viralizando e gerando uma receita substancial via publicidade. Testemunhando o caráter exclusivamente pecuniário do empreendimento, os dois jovens responsáveis por ele, que se identificam como os "novos jornalistas marrons", cogitam a criação de um site liberal com perfil correlato. Outra reportagem, que aparece no BuzzFeed também na época eleitoral (SILVERMAN; ALEXANDER, 2016), detecta mais de cem sites ativos de política norte-americana registrados na pequena cidade de Veles, na Macedônia, e mantidos por jovens locais. Estes descobrem que os anúncios clicados por internautas estadunidenses oferecem um rendimento superior e que a maneira mais fácil de angariar retorno nos anúncios para tais internautas é postar notícias sensacionalistas, usualmente falsas, copiadas de sites de direita e orientadas para os partidários de Trump, divulgando-as então no Facebook para alavancar o tráfego. Como o ecossistema das redes impõe a competição por atenção numa conjuntura polarizada, que favorece quem guarda uma relação elástica com os fatos, ele coloca pressão sobre as organizações jornalísticas, capturadas no que parece quase um jogo de soma zero entre sucesso e rigor. Ademais, mesmo que obtenha algum êxito nessa competição, resta ao jornalismo o desafio de adaptar seu modelo de negócios para capitalizar financeiramente a atenção conquistada, algo que fontes trabalhando deliberadamente com notícias fraudulentas não parecem ter tanta dificuldade em equacionar.

Adicionalmente, a onimediação desigual pode implicar uma desresponsabilização, seja do ponto de vista legal, seja do ponto de vista prático. Como não é indispensável zelar por um nome para intervir nas plataformas, proliferam fontes pseudojornalísticas. E uma fração significativa da transmissão de notícias fraudulentas incumbe aos usuários comuns das redes, que, a pretexto de estarem simplesmente repassando o que receberam, eximem-se de sua responsabilidade. Em pesquisa feita nos Estados Unidos em dezembro de 2016 (BARTHEL; MITCHELL; HOLCOMB, 2016), 14\% dos interrogados admitem ter difundido notícias fraudulentas conscientemente (com a intenção deliberada de desinformar, para denunciá-las como falsas, por divertimento ou por alguma outra razão) e 16\% admitem tê-lo feito inadvertidamente. Como alguns o fizeram em ambas as circunstâncias, ao todo 23\% reconhecem seu papel em espalhar essas notícias. No WhatsApp, em que a vigilância por parte da plataforma é menor, os usuários integram grupos menores e com pessoas mais próximas e as mensagens encaminhadas não exibem o remetente inicial, o compromisso de cada um com a legitimidade do que posta tende a diminuir mais ainda. A desresponsabilização pode ser associada ao "efeito de terceira pessoa" (DAVISON, 1983), quando alguém supõe que os outros são mais suscetíveis a mensagens propagandísticas do que ele ou seu grupo, efeito também verificado no caso da desinformação (JANG; KIM, 2018); um dos riscos, aqui, é que o usuário atue como correia de transmissão da desinformação, ou a tolere, sem atinar com seu próprio envolvimento.

\section{Arena de atenção}

No início da década de 1960, Habermas (1990) introduz o conceito de "esfera pública", na qual a mediação jornalística desempenha função essencial, pois ela abrange espaços dedicados a uma discussão racional estimulada amiúde por materiais oriundos da imprensa. Já o título de sua obra, porém, alerta-nos que estamos em face de uma "categoria da sociedade burguesa" sujeita a uma "mudança 
estrutural". Ao longo do texto, essa mudança é retratada como um esvaziamento progressivo iniciado em fins do século XIX e relacionado a uma gama de fatores, entre os quais o advento da comunicação de massa, que engendra uma "esfera pública apenas em aparência" (HABERMAS, 1990, p. 171), desprovida de canais adequados para o debate. A partir dos anos 1990, alguns vislumbram uma oportunidade de reverter esse panorama por meio da Internet, que "pode ajudar a revitalizar a esfera pública" em novas bases, como uma espécie de "ágora eletrônica" (RHEINGOLD, 1994, p. 14). É bom que se diga, no entanto, que o próprio Habermas (2006, p. 423) se mostra reticente a respeito: "No contexto de regimes liberais, a ascensão de milhões de salas de bate-papo fragmentadas em todo o mundo [...] tende a levar à fragmentação de audiências de massa amplas mas politicamente direcionadas em um enorme número de públicos em torno de questões isoladas". Ora, nas plataformas geridas por algoritmos, fica claro que o modelo habermasiano é ainda menos aplicável.

Se a esfera pública pressupõe autonomia vis-à-vis o mercado, as plataformas são empreendimentos cujo modelo de negócios se alicerça na participação dos usuários, como consumidores de anúncios ou de produtos e serviços. Os algoritmos, que regem seu funcionamento, procuram incentivar essa participação, exibindo a cada um os conteúdos que teriam maior chance de atraí-lo. Isso implica que quem cria e dissemina conteúdos nas plataformas - incluindo os múltiplos líderes de opinião que nelas atuam e, em última instância, cada usuário individualmente - é incitado a calcular o que potencialmente reverberaria mais, granjearia maior sucesso, faria seus conteúdos sobressaírem-se em comparação com outros. Portanto, a plataforma algorítmica não opera exatamente como esfera pública. Muito mais relevante do que o conceito habermasiano, nesse caso, é a ideia de arena de atenção. "Arena" deve ser lida tanto na acepção de ambiente onde prevalece a lógica do espetáculo, no qual se almeja destaque, quanto na de fórum onde se rivaliza com os demais, no qual se tenta superar os concorrentes.

Nessa contenda, amalgamam-se numa espécie de liquidificador interesses variegados e contatos provenientes de diversas áreas da vida. Há, por conseguinte, uma hibridização de itens públicos e privados, dissipando-se a barreira que a esfera pública erige entre eles. Em contraste com o que ocorre nesta, território por excelência da argumentação racional, as emoções representam um trunfo na batalha por atenção (BERGER; MILKMAN, 2012). Ademais, a emulação incessante distingue-se da busca de entendimento, e da consequente conotação de orientação unificadora, atributo da esfera pública. E, se esta exerce uma influência moderadora nos foros institucionais, ambicionando desse modo contribuir para uma suposta democratização do exercício do poder, na arena de atenção prevalecem as conveniências dos atores em conflito.

O usuário das plataformas figura nelas em condição dupla: de quem tem sua atenção atraída e de quem atrai a atenção de outros. Ele coloca-se nas plataformas como um receptor privilegiado, de alguém que espera delas, ou mais precisamente dos algoritmos que as governam, ser apresentado aos conteúdos que lhe são mais caros. Trata-se de um consumidor ubíquo, defronte do qual se abre um leque de opções customizadas consoante suas predileções, que competem para cativá-lo. Simultaneamente, o usuário está no lugar de emissor privilegiado, de alguém que pode atingir outros sem grande esforço. Ele é um agente ubíquo de micropropaganda: até quando não publica algo original, ao acessar, curtir, comentar ou compartilhar algum conteúdo está auxiliando a promovê-lo. Seja impelido pela autovalorização narcísica, pelo ativismo político ou por qualquer outra motivação, de alguma forma ele tende a engajar-se na luta por atenção. Esse engajamento o instiga às vezes a opinar sobre temas que não domina, devido àquilo que é qualificado como efeito Dunning-Kruger, a dificuldade em perceber as limitações de seu conhecimento. 
A capacidade de captar a atenção, nas plataformas, é aferida pelo valor-algoritmo. Os mesmos fatores pesam em ambos os sentidos: daquilo que é exibido ao usuário e chama sua atenção, e daquilo que ele divulga para chamar a atenção dos outros. O encadeamento desses dois processos acarreta o sucesso das viralizações, quando cada um recebe um conteúdo, reputa-o interessante e repassa-o a outros. Um conteúdo sedutor faz com que o usuário o consuma e (se tal conteúdo não concerne especificamente a quem o publicou) concomitantemente seja induzido a compartilhá-lo, supondo que ele provocará em outros impressão similar à que causou em si. Algo é viralizável quando é percebido como digno, quer de ser consumido, quer de ser enviado a outros. Isso se traduz em seu valor-algoritmo.

$\mathrm{O}$ valor-algoritmo mais elevado para cada usuário impacta a intensidade de sua atenção, ou seja, o nível de interação dele com cada conteúdo e a extensão da atenção, ou seja, o tempo que ele permanece na plataforma e a quantidade de conteúdos com os quais ele interage. Na perspectiva da plataforma, obter o maior valor-algoritmo para cada usuário requer sua eficiência em discriminar em meio à enxurrada de conteúdos aquilo com o dom de atraí-lo. Na perspectiva de quem, qualquer que seja sua motivação, deseja engajar outros, lograr o valor-algoritmo mais alto depende de sua aptidão em produzir ou reproduzir conteúdos com apelo para o público-alvo. Isso envolve explorar as especificidades de cada plataforma: há toda uma indústria que se dedica a descobrir expedientes para aumentar o ranqueamento no Google ou as recomendações no YouTube (BISHOP, 2020).

Os fatores que prendem a atenção são, muitas vezes, justamente aqueles que colaboram para a desinformação. Num artigo embasado em extenso levantamento no Twitter, no qual concluem que os boatos se alastram mais depressa e para um universo maior de pessoas do que as notícias genuínas, pesquisadores do Massachusetts Institute of Technology (MIT) observam que seu grau de novidade é maior (VOSOUGHI; ROY; ARAL, 2018). Isso não é difícil de entender: o que é patentemente falso provavelmente não será encontrado nos canais costumeiros de notícias, logo soa como novo. É igualmente compreensível que esse ar de ineditismo faça com que se saliente. Além disso, é natural que quem detém o que parece ser uma informação nova se sinta privilegiado e a compartilhe para assim se vangloriar de seu status. O mesmo estudo aponta que outro motor da desinformação são as emoções, entre as quais sobressaem a surpresa (que se coaduna com o semblante de novidade), o medo e o desgosto (que têm o potencial de mobilizar o usuário a ponto de que ele se empenhe em propalar certos conteúdos).

\section{Exposição calibrada}

Não é de se estranhar que veículos jornalísticos alinhem a seu redor setores sociais que perfilhem suas posições. Nas últimas décadas, a polarização na sociedade, na forma da explosão de "guerras culturais" (HUNTER, 1991), também se manifesta na mídia tradicional, com a cristalização de nichos noticiosos que refletem a segmentação ideológica do público (STROUD, 2011).

As próprias redes sociais offline têm uma tendência à homofilia, o agrupamento de indivíduos com afinidades entre si (MCPHERSON; SMITH-LOVIN; COOK, 2001). Essa tendência está presente, outrossim, em redes digitais, ainda que não haja um viés algorítmico nesse sentido, ou que se adote um viés para contrabalançá-la (BLEX; YASSERI, 2020). Na prática, o modelo de negócios das plataformas acentua a propensão à homofilia. As redes que se constituem entre os usuários são administradas com o auxílio de algoritmos que inferem seus interesses do exame de seus padrões de atividade, exibindo-lhes a partir daí conteúdos selecionados conforme a adequação a tais interesses. Assim, os algoritmos concorrem para a exposição seletiva, direcionando o usuário a enfoques congruentes com o seu. A possibilidade de ter sua atenção atraída, bem como a de atrair a 
atenção dos outros, aumenta entre semelhantes. Isso pode redundar no encapsulamento em conjuntos homogêneos, as "câmaras de eco" (SUNSTEIN, 2007) ou "bolhas de filtro" (PARISER, 2011). No dia seguinte ao referendo no Reino Unido que aprova o Brexit, o ativista britânico Tom Steinberg (2016) relata:

Estou procurando ativamente no Facebook pessoas celebrando a vitória do Brexit, mas a bolha é TÃO forte, e estende-se TÃO longe em coisas como a busca personalizada do Facebook, que não consigo achar ninguém que esteja feliz, apesar do fato de que mais da metade do país está claramente em júbilo hoje e apesar do fato de que estou ativamente procurando ouvir o que estão dizendo. (STEINBERG, 2016, grifo do autor).

A homofilia desdobra-se em segregação - o afastamento em relação àqueles com os quais há discordâncias -, que é tanto endógena (por opção do usuário) quanto exógena (por obra do algoritmo); ambas se alimentam mutuamente.

Autores como Bruns (2019) questionam a existência de câmaras de eco e bolhas de filtro. Seus argumentos, escorados na análise de dados empíricos, podem ser sumarizados na constatação de que a mecânica das plataformas não veda completamente o acesso a visões discrepantes daquelas do usuário. Isso em princípio é procedente, pois, ainda que alguém tente restringir seus laços aos que concordam consigo, cedo ou tarde vai acabar deparando-se com um amigo de infância, um primo distante ou um colega de trabalho que pensa diferentemente. E até aqueles que comungam com suas ideias o fazem entrar em contato com posições que normalmente estariam fora de seu radar, ao trazerem, por exemplo, artigos de jornal ou declarações de políticos com o intuito de questioná-los. Seria necessário, contudo, que a câmara de eco ou bolha de filtro fosse absoluta para atestar que ela está presente? Não bastaria notar que o grosso da dieta informativa de alguém segue uma única diretriz, ou que os pensamentos divergentes com que ele se depara já vêm enquadrados? Que efeito, convenhamos, poderia ter uma matéria da mídia mainstream (um jornal como Folha de S.Paulo ou The New York Times) sobre quem julga inclusive essa mídia como esquerdista? De toda sorte, uma alternativa mais precisa, no lugar de câmara de eco ou bolha de filtro, ou mesmo de exposição seletiva, seria falar em exposição calibrada. Há situações em que outros pontos de vista chegam ao usuário, mas em volume reduzido e sob ângulos determinados, por força da calibragem dos algoritmos, que potencializa suas escolhas.

Na exposição calibrada, o valor-algoritmo corresponde ao fundamento da calibragem. Há aí uma dinâmica de retroalimentação: na medida em que o valor-algoritmo é confirmado, ou seja, o usuário efetivamente dá preferência àquilo que a plataforma lhe recomenda, a calibragem se refina, se torna mais acurada, o que sinaliza que a exposição se tornará ainda mais calibrada. Essa dinâmica é marcante em fenômenos associados a esse gênero de exposição. É o caso do viés de confirmação: cada um é naturalmente mais receptivo àquilo que condiz com suas crenças. Ou das teorias da conspiração: se outros acreditam nelas, isso vale como endosso; se não acreditam, é interpretado como indício de que são vítimas ou cúmplices da conspiração. Ou das inclinações segregacionistas, por exemplo em termos ideológicos: se os que estão à minha volta concordam comigo, isso fortalece meu elo com eles.

A exposição calibrada revela-se bastante propícia à desinformação. Conteúdos que distorcem a realidade ou não têm respaldo nela exigem, para viralizar, uma audiência especialmente receptiva. Além de permitirem que determinados tipos de desinformação (digamos, em proveito de um candidato e contra seus adversários) sejam encaminhados para um público mais disposto a aceitá-los, os algoritmos também conservam à distância deste conteúdos que possam contrapor-se à desinformação, como aqueles elaborados por agências de checagem de dados. De resto, graças aos algoritmos, a atitude receptiva de certos usuários diante de conteúdos falsos reforça-se pelo convívio virtual com outros usuários 
com postura congênere. O nexo entre desinformação e exposição calibrada é ratificado por diversos trabalhos empíricos (TÖRNBERG, 2018; GUESS; NYHAN; REIFLER, 2018; SPOHR, 2017). Uma ilustração pertinente é-nos fornecida pelo terraplanismo: uma fantasia antes absolutamente marginal é bafejada pelos algoritmos em plataformas como o YouTube, que possibilitam a seus adeptos se articularem, ganharem visibilidade e impulsionarem material em prol de sua causa (MOHAMMED, 2019).

\section{Máquinas de guerra híbrida}

O rótulo de guerra híbrida tem sido utilizado para designar uma modalidade de luta política assentada na desestabilização permanente, que se presta a abalar um regime, a disputar um pleito ou a governar. A guerra híbrida pode assumir a forma de um movimento horizontal, como o de Junho de 2013 no Brasil e o dos coletes amarelos em 2018 na França, ou de uma organização centralizada mas com cunho antissistema, na linha da "máquina de guerra" de Deleuze e Guattari (1980). No último caso, temos o que pode ser chamado de "máquina de guerra híbrida", como a campanha do Brexit ou as campanhas presidenciais de Trump, na eleição norte-americana de 2016 (CASTRO, 2020a), e de Jair Bolsonaro, na eleição brasileira de 2018 (CASTRO, 2020b).

As plataformas algorítmicas são dispositivos talhados para a operação das máquinas de guerra híbrida, que aliam as vantagens da horizontalidade das redes com as de uma coordenação central. Elas forjam autênticas milícias digitais, concatenando a ação de voluntários, movidos por afinidade ideológica, com a de serviços contratados. As campanhas do Brexit e de Trump recorrem à mesma empresa de consultoria, a Cambridge Analytica, que customiza a propaganda de acordo com o perfil psicográfico dos usuários das redes sociais. Junto com usuários reais, são arregimentados robôs e contas falsas. As máquinas de guerra híbrida mantêm comando e estrutura paralelos aos das plataformas, como se fossem miniplataformas em seu interior. Conquanto nem sempre obedeçam às normas de conduta impostas aos usuários em geral, gozam de relativa complacência nesse aspecto, seja à custa de sua força social e política, seja por carrearem recursos para as plataformas, diretamente (ao contratarem serviços, como anúncios) ou indiretamente (ao fomentarem maior participação). Sua atuação é polarizadora, mas, sobrepujando os adversários em organização, coesão e ânimo militante, trata-se de uma "polarização assimétrica" (BENKLER; FARIS; ROBERTS, 2018).

A desinformação, cuja importância é reconhecida nos manuais militares no transcorrer da história, está no cerne das máquinas de guerra híbrida, contribuindo decisivamente para sua fachada antissistema. Se as plataformas algorítmicas, por conta de suas características tecnológicas e seu modelo de negócios, favorecem a desinformação, isso é potencializado pela ação das máquinas de guerra híbrida. A onimediação desigual, a arena de atenção e a exposição calibrada impulsionam a desinformação, como vimos, mesmo na falta de uma atividade coordenada no âmbito das plataformas. A intervenção das máquinas de guerra híbrida leva isso muito mais longe, uma vez que elas se dedicam à manufatura de desinformação em escala industrial, com base em planejamento estratégico e disciplina metódica, multiplicando seu alcance e ressonância. Tal fenômeno dissemina-se globalmente: um relatório do Oxford Internet Institute (BRADSHAW; HOWARD, 2019, p. 2) cita evidências de um número crescente de campanhas sistemáticas de manipulação em plataformas de mídias sociais, afetando 28 países em 2017, 48 em 2018 e 70 em 2019.

São as vitórias do Brexit e de Trump em 2016, impulsionados maciçamente pela desinformação, que colocam na ordem do dia a discussão sobre notícias fraudulentas e pós-verdade. No Brasil, a problemática da desinformação ganha corpo 
com o triunfo de Bolsonaro, em 2018. A exemplo da campanha de Trump, a de Bolsonaro monta uma estratégia conjugando várias plataformas, em que pese uma diferença relevante: a ênfase no WhatsApp, reflexo, em parte, das providências contra a desinformação tomadas por corporações como o Facebook. Vale assinalar que as cruzadas de desinformação promovidas mediante máquinas de guerra híbrida podem inclusive atravessar as fronteiras nacionais (COSENTINO, 2020).

\section{Considerações finais}

Deve-se ter em mente que, além de enraizar-se na articulação entre algoritmos e modelos de negócios nas plataformas, a desinformação é tributária do cenário político no período recente.

A expansão das plataformas algorítmicas coincide com a hegemonia do neoliberalismo (CASTRO, 2016b) e seu funcionamento guarda afinidade com a lógica de mercado peculiar a este. Nesse quadro, os algoritmos equivalem a uma "instância de veridição", isto é, de estabelecimento da verdade, que Foucault (2004, p. 35) associa ao mercado. Os conteúdos são avaliados nas plataformas mormente pelo prisma da circulação: predominam aqueles que conseguem maior repercussão. Na expressão de Dean (2009), vivemos em um "capitalismo comunicativo", no qual o valor de uso da mensagem é obscurecido por seu valor de troca, mensurado pela circulação. Nesse contexto, a verdade não é definida pela correspondência ao factual, mas pelo cômputo de visualizações, curtidas, comentários e compartilhamentos.

A isso se acrescenta uma inflexão a partir da crise de 2008, a maior até então do capitalismo desde 1929. O neoliberalismo vivencia um processo de erosão de legitimidade, ainda que, face à carência de alternativas com suficiente apoio social, retenha sua dominância. Ele sofre, entretanto, uma mutação, transformando-se num hiper neoliberalismo, no qual se exacerbam as dimensões de desestabilização, exploração e autoritarismo. Essa quadra de intensificação dos antagonismos sociais serve de pano de fundo para a emergência de máquinas de guerra híbrida e para o alastramento da desinformação nos últimos anos.

Cabe também sublinhar que o liame entre plataformas algorítmicas e desinformação não nos autoriza a entronizar automaticamente os veículos jornalísticos tradicionais como paradigmas de confiabilidade. Nos Estados Unidos, jornais de prestígio como The New York Times e The Washington Post apoiaram em passado recente a Guerra do Iraque, cuja justificativa, o pretenso arsenal de destruição em massa de que disporia Saddam Hussein, se revelou uma farsa. No Brasil, a grande mídia teve papel crucial nos episódios de guerra híbrida que desembocaram na chegada ao poder da extrema-direita. Adicionalmente, é mister cautela para não incidir em uma postura acrítica com respeito às agências de checagem, que se arvoram em watchdogs perante a desinformação, mas não são neutras, estando vinculadas frequentemente a órgãos de mídia mainstream e fundações privadas cuja agenda se confunde com a do neoliberalismo.

\section{Referências}

BARTHEL, M.; MITCHELL, A.; HOLCOMB, J. Many Americans believe fake news is sowing confusion. Pew Research Center, Dez. 2016.

BENKLER, Y.; FARIS, R.; ROBERTS, H. Network propaganda: manipulation, disinformation, and radicalization in American politics. New York: Oxford University Press, 2018. 
BERGER, J.; MILKMAN, K. L. What makes online content viral? Journal of Marketing Research, v. 49, n. 2, p. 192-205, 2012.

BISHOP, S. Algorithmic experts: selling algorithmic lore on YouTube. Social Media + Society, p. 1-11, Jan-Mar 2020.

BLEX, C.; YASSERI, T. Positive algorithmic bias cannot stop fragmentation in homophilic networks. Journal of Mathematical Sociology, 2020.

BRADSHAW, S.; HOWARD, P. N. The global disinformation order: 2019 global inventory of organised social media manipulation. Working Paper 2019.2. Oxford: Project on Computational Propaganda, 2019.

BRUNS, A. Are filter bubbles real? Cambridge (UK) and Medford: Polity Press, 2019.

CASTRO, J. C. L. de. Das massas às redes: comunicação e mobilização política. In: JESUS, E.; TRINDADE, E.; JANOTTI, J.; ROXO, M. (Org.). Reinvenção comunicacional da política: modos de habitar e desabitar o século XXI. Salvador: EDUFBA/Brasília: Compós, 2016a. p. 149-166.

CASTRO, J. C. L. de. Social networks as dispositives of neoliberal governmentality. Journal of Media Critiques, v. 2, n. 7, p. 85-102, 2016b.

CASTRO, J. C. L. de. Redes sociais como modelo de governança algorítmica. Matrizes, v. 12, n. 2, p. 165-191, mai./ago. 2018.

CASTRO, J. C. L. de. Plataformas algorítmicas: interpelação, perfilamento e performatividade. Revista Famecos, v. 26, n. 3, p. 1-24, set./dez. 2019a.

CASTRO, J. C. L. de. Da lógica editorial à lógica algorítmica da notícia. Conexão - Comunicação e Cultura, v. 18, n. 36, p. 36-56, jul./dez. 2019 b.

CASTRO, J. C. L.s de. Máquinas de guerra híbrida em plataformas algorítmicas. E-Compós, v. 23, p. 1-29, 2020a.

CASTRO, J. C. L. de. Neoliberalismo, guerra híbrida e a campanha presidencial de 2018. Comunicação \& Sociedade, v. 42, n. 1, p. 261-291, jan./abr. 2020 b.

COSENTINO, G. Social media and the post-truth world order: the global dynamics of disinformation. Cham: Palgrave Pivot, 2020.

DAVISON, W. P. The third-person effect in communication. Public Opinion Quarterly, v. 47, n. 1, p. 1-15, Spring 1983.

DEAN, J. Democracy and other neoliberal fantasies: communicative capitalism and left politics. Durham and London: Duke University Press, 2009.

DELEUZE, G.; GUATTARI, F. Mille plateaux: capitalisme et schizophrénie. Paris: Minuit, 1980.

FOUCAULT, M. Naissance de la biopolitique: cours au Collège de France, 19781979. Paris: Gallimard/Seuil, 2004. 
FREUD, S. Massenpsychologie und Ich-Analyse. In: FREUD, S. Gesammelte Werke, dreizehnter Band: Jenseits des Lustprinzips / Massenpsychologie und Ich-Analyse / Das Ich und das Es. 5. Aufl. Frankfurt am Main: S. Fischer, 1967. p. 71-161.

GALLUP/KNIGHT FOUNDATION. An online experimental platform to assess trust in the media. Knigh Foundation, 2018. Disponível em: $<$ https://knightfoundation.org/wp-content/uploads/2020/02/KnightFoundation_NewsLens1_Client_ Report_070918_ab.pdf>. Acesso em: 30 set. 2020.

GALTUNG, J.; RUGE, M. H. The structure of foreign news: the presentation of the Congo, Cuba and Cyprus crises in four Norwegian newspapers. Journal of Peace Research, v. 2, n. 1, p. 64-91, 1965.

GRAHAM, T.; WRIGHT, S. Discursive equality and everyday talk online: the impact of "superparticipants". Journal of Computer-Mediated Communication, v. 19, n. 3, p. 625-642, Apr. 2014.

GUESS, A. M.; NYHAN, B.; REIFLER, J. Exposure to untrustworthy websites in the 2016 U.S. election. 2018. Disponível em: <https://www.dartmouth. edu/ nyhan/fake-news-2016.pdf >. Acesso em: 30 set. 2020.

HABERMAS, J. Strukturwandel der Öffentlichkeit: Untersuchungen zu einer Kategorie der bürgerlichen Gesellschaft. Neuaufl. Frankfurt am Main: Suhrkamp, 1990.

HABERMAS, J. Political communication in media society: does democracy still enjoy an epistemic dimension? The impact of normative theory on empirical research. Communication Theory, v. 16, n. 4, p. 411-426, Nov. 2006.

HARCUP, T.; O'NEILL, D. What is news? Galtung and Ruge revisited. Journalism Studies, v. 2, n. 2, p. 261-280, 2001.

HARCUP, T.; O’NEILL, D. What is news? News values revisited (again). Journalism Studies, v. 18, n. 12, p. 1470-1488, 2017.

HOLMES, D. Whisper EIC: "It's not important if a story's real, the only thing that really matters is whether people click on it”. Pando, Jul. 2014.

HUNTER, J. D. Culture wars: the struggle to define America. New York: Basic Books, 1991.

IPSOS. Fake news, filter bubbles, post-truth and trust: a study across 27 countries. Ipsos, 2018. Disponível em: <https://www.ipsos.com/sites/default/files/ct/news/ documents/2018-08/fake_news-report.pdf >. Acesso em: 30 set. 2020.

JANG, S. M.; KIM, J. K. Third person effects of fake news: fake news regulation and media literacy interventions. Computers in Human Behavior, v. 80, p. 295 302, Mar. 2018.

KATZ, E.; LAZARSFELD, P. F. Personal influence. New York: Free Press, 1955.

LAZARSFELD, P. F.; BERELSON, B.; GAUDET, H. The people's choice: how the voter makes up his mind in a presidential campaign. New York: Columbia University Press, 1944. 
LEWIN, K. Forces behind food habits and methods of change. Bulletin of the National Research Council, n. 108, p. 35-65, Oct. 1943.

McCOY, T. For the "new yellow journalists," opportunity comes in clicks and bucks. The Washington Post, Nov. 2016.

McPHERSON, M.; SMITH-LOVIN, L.; COOK, J. M. Birds of a feather: homophily in social networks. Annual Review of Sociology, v. 27, n. 1, p. 415-444, Aug. 2001.

MOCANU, D., et. al. Collective attention in the age of (mis)information. Computers in Human Behavior, v. 51, p. 1198-1204, 2015.

MOHAMMED, S. N. Conspiracy theories and flat Earth videos on YouTube. Journal of Social Media in Society, v. 8, n. 2, p. 84-102, Fall 2019.

MUNGER, K. All the news that's fit to click: the economics of clickbait media. Political Communication, v. 37, n. 3, p. 376-397, 2020.

PARISER, E. The filter bubble: What the Internet is hiding from you. New York: Penguin Press, 2011.

RHEINGOLD, $\mathrm{H}$. The virtual community: homesteading on the electronic frontier. New York: HarperPerennial, 1994.

SCHERER, É. La révolution numérique. Paris: Dalloz, 2009.

SILVERMAN, C.; ALEXANDER, L. How teens in the Balkans are duping Trump supporters with fake news. Buzzfeed, 2016. Acesso em: 08 out. 2021.

SPOHR, D. Fake news and ideological polarization: filter bubbles and selective exposure on social media. Business Information Review, v. 34, n. 3, p. 150-160, 2017.

SRNICEK, N. Platform capitalism. Cambridge (UK) and Malden: Polity, 2017.

STEINBERG, T. Facebook post. Facebook, 2016. Disponível em: $<$ https://www. facebook.com/tom.steinberg.503/posts/10157028566365237>. Acesso em: 30 set. 2020.

STROUD, N. J. Niche news: the politics of news choice. Oxford and New York: Oxford University Press, 2011.

SUNSTEIN, C. R. Republic.com 2.0. Princeton and Oxford: Princeton University Press, 2007.

TARDE, G. L'opinion et la foule. 3ème ed. Paris: Félix Alcan, 1910.

TÖRNBERG, P. Echo chambers and viral misinformation: modeling fake news as complex contagion. PLoS ONE, v. 13, n. 9, 2018.

VOSOUGHI, S.; ROY, D.; ARAL, S. The spread of true and false news online. Science, v. 359, n. 6380, p. 1146-1151, Mar. 2018.

WHITE, D. M. The "gate keeper": a case study in the selection of news. Journalism Quaterly, v. 27, n. 4, p. 383-390, 1950. 